\title{
Projeto de Criação do Curso de Licenciatura em Geociências e Educação Ambiental - Instituto de Geociências/USP
}

\author{
Maria Cristina Motta de Toledo' (mcristol@usp.br), Arlei Benedito Macedo', Rômulo Machado², \\ Veridiana Teixeira de Souza Martins' ${ }^{1}$ Claudio Riccomini' ${ }^{\text {, Paulo Roberto dos Santos }}{ }^{1}$, \\ Marcos Egydio da Silva², Wilson Teixeira ${ }^{2}$ \\ 'Departamento de Geologia Sedimentar e Ambiental - Instituto de Geociências - USP \\ R. do Lago 562, CEP 05508-080, São Paulo, SP, BRA \\ ${ }^{2}$ Departamento de Mineralogia e Geotectônica - Instituto de Geociências - USP, São Paulo, SP, BRA
}

Recebido em 11 de julho de 2003; aceito em 14 de março de 2005

Palavras-chave: Geociências e educação ambiental, licenciatura, educação em Geociências.

\section{RESUMO}

O curso de Licenciatura em Geociências e Educação Ambiental tem duração de 4 anos, 40 vagas e é um novo curso, noturno, criado em 2003, no Instituto de Geociências da Universidade de São Paulo. O licenciado formado difundirá o conhecimento integrado da natureza, destacando a ligação entre a história da vida e história geológica da Terra e as relações dos fenômenos naturais com os conteúdos abordados pela Física e pela Química, estendendo os processos naturais terrestres para a esfera da vida cotidiana da humanidade atual, e fazendo a ligação, portanto, dos processos naturais com os problemas ambientais. O profissional atuará na educação escolar, no ensino fundamental, médio e técnico, e não escolar, que abrange atividades em centros de educação ambiental ligadas ao planejamento com preocupações ecológicas, como museus, centros de Ciência, bibliotecas, parques, associações civis, ONGs, empresas ligadas ao planejamento de atividades de turismo com preocupações ecológicas ou com programas de educação ambiental. Sua atuação suprirá a lacuna de conhecimento sobre a Terra, materiais e processos geológicos e riscos urbanos, além de contribuir para a formação de cidadãos conscientes no uso e ocupação do meio natural e sensíveis aos problemas ambientais. Este artigo apresenta com detalhes o projeto de criação deste curso, seus objetivos, sua estruturação, enfatizando a importância das Geociências para a educação, em geral, e para a educação ambiental, em particular.

Keywords: Geosciences and environmental education, teaching degree, Geoscience education.

\section{ABSTRACT}

In 2003, the Institute of Geosciences of the University of São Paulo created a four-year night course designed to provide a Teaching Degree in Geosciences and Environmental Education for 40 students per year. Graduates with this degree will be able to provide a holistic view of nature, especially with respect to: the relationships between the history of life and the geologic history of planet Earth; how natural phenomena relate to basic principles of physics and chemistry; and how natural earth processes affect daily life, thereby showing the links between natural processes and environmental problems. These professionals will be able to participate in scholastic education at the elementary, middle-school and technical-school levels as well as in extra-scholastic environmental education, such as at museums, science centers, libraries, public park systems, civil associations, NGOs, companies linked to ecological planning and/or ecological tourism, and environmental education programs. These professionals will help close the large gap in knowledge at all levels of Brazilian society with regard to the Earth and its natural materials, processes, and perils, both urban and rural; they will also contribute to the formation of informed citizens both aware of the necessity for the conscientious use and occupation of the environment and sensitive to environmental problems. This paper describes in detail the creation, objectives, and structure of this new course and emphasizes the importance of the Earth Sciences in Education in general and in Environmental Education in particular. 


\section{INTRODUÇÃO}

O conhecimento da dinâmica e características do meio físico e de suas interações perante as múltiplas atividades humanas é essencial para que as mesmas ocorram de modo equilibrado, minimizando o seu impacto ambiental e ajudando na busca de soluções para os problemas já existentes de degradação do ambiente. O caráter curioso, inteligente e engenhoso da espécie humana tem sido causa de alterações imensas no seu habitat, mesmo além de seus limites originais, explorando as possibilidades para melhoria de qualidade de vida. Estas alterações estão colocando em risco a própria sobrevivência da Biosfera, embora o desenvolvimento da sociedade mostre um aumento progressivo no nível de conforto e de longevidade para a espécie humana em alguns países. Partindo do princípio de que as ações antrópicas que degradam o ambiente são principalmente fruto de desconhecimento, é inevitável concluir a urgência em difundir o conhecimento na área. Isto contribuirá para a formação de cidadãos críticos e responsáveis com relação à ocupação e à utilização dos recursos naturais do planeta, compromissados com o futuro da humanidade, em geral, e com a sustentabilidade do desenvolvimento e, assim, afetará decisivamente a formação de uma base social da qual sairão, futuramente, os futuros políticos, empresários e tomadores de decisão, cujo grau de conhecimento sobre os processos naturais terrestres será decisivo para refrear a gravidade dos problemas e impactos atualmente vivenciados pela humanidade.

A cultura em Ciências da Terra da população brasileira é ou quase nula ou imprecisa e, muitas vezes, equivocada, já que há apresentação dos temas nesta área como inserções dispersas, fragmentadas e desconectadas do ciclo natural em outras disciplinas escolares como Ciências, Geografia, Biologia, Química e Física. A apresentação de aspectos isolados do aproveitamento do meio e de seus materiais, abordados por diversas disciplinas, pode levar a uma idéia muito imediatista e utilitária da natureza, o que apresenta o risco de preservar ações potencialmente destrutivas, cujos exemplos são, infelizmente, comuns nos dias atuais. Assim, raros são os cidadãos que têm real noção do funcionamento do planeta e consciência de que o grau crescente de ocupação da superfície e da exploração dos recursos (minerais, energéticos e hídricos) significa uma importante interferência no curso natural da evolução da superfície terrestre.

O Instituto de Geociências da Universidade de São Paulo, ciente de sua responsabilidade para o aperfeiçoamento da educação no país, tem tomado uma série de iniciativas, algumas das quais já têm paralelo em outras instituições, visando a divulgar, de várias formas, o conhecimento sobre a dinâmica natural com a qual a origem e a evolução da vida mantêm relações de total interdependência, complementando o estudo das Ciências da Natureza normalmente efetuado na educação escolar.

Uma das ações já realizadas foi a preparação e publicação do livro Decifrando a Terra (Teixeira et al., 2000); este livro, com uma aceitação significativa, recebeu a menção honrosa do prêmio Jabuti da Câmara Brasileira do Livro em 2001. Outra ação refere-se à abertura do Museu de Geociências, visitado anualmente por algumas dezenas de milhares de estudantes do ensino fundamental e médio, acompanhados por seus professores, e que recebem um atendimento visando a despertar a curiosidade e o interesse pelos materiais lá expostos e pelos processos que os geraram e os transformaram. Uma atividade mais recente refere-se a visitas dos docentes e estudantes de Geologia a escolas com a apresentação de palestras sobre as Geociências e sobre as profissões ligadas às Ciências da Terra, enfatizando o papel do conhecimento nestas áreas no desenvolvimento da sociedade. Várias dessas ações são decorrência de solicitação direta da comunidade, demonstrando a demanda crescente pela participação das Geociências no universo escolar.

Outra ação foi a criação da Licenciatura em Geociências e Educação Ambiental, que visa a preencher a lacuna deixada na atividade dos profissionais em Geociências várias décadas atrás, quando a História Natural foi desmembrada em Biologia e Geologia. Desde então, os profissionais em Ciências da Terra praticamente não têm se ocupado do ensino, e as descobertas e avanços nas Geociências restringiram-se aos círculos especializados, ficando a escola brasileira privada de informações geocientíficas precisas, atualizadas e integradas, o que prejudica a conscientização sobre a complexa dinâmica do planeta. Assim, espera-se que os egressos deste novo curso participem da formação de indivíduos capazes de opinar de forma consciente sobre as questões de ocupação e uso do ambiente pela sociedade, aproximando-a, assim, do caminho rumo ao desenvolvimento sustentável e aos objetivos das diretrizes curriculares traçadas para a educação básica.

O curso de Licenciatura em Geociências e Educação Ambiental pretende formar profissionais educadores que possam contribuir ativamente para o efetivo alcance dos objetivos dos Parâmetros Curriculares Nacionais (PCN) (Brasil, 1999), e complementa o ensino de Ciências Naturais com conteúdos geocientíficos, 
somados aos conteúdos de Geografia e de Biociências, para formar indivíduos responsáveis e comprometidos com o futuro da sociedade. No caso da Geografia, a disciplina está inserida em Ciências Humanas e abrange o tempo das relações entre humanidade e natureza, ou seja, milhares de anos apenas, enquanto o planeta e a Vida evoluem há bilhões de anos, e abrange a superfície terrestre apenas, quando o subsolo tem intensa interação com a superfície. Os conteúdos de Biociências, por sua vez, tratam dos seres vivos sem entrar nas questões ambientais que definiram as circunstâncias evolutivas que foram, por sua vez, profundamente modificadas pela atividade orgânica desde a origem da Vida, quase quatro bilhões de anos atrás.

\section{OBJETIVOS DO CURSO E PERFIL DO GRADUADO}

O curso de Licenciatura em Geociências e Educação Ambiental, planejado dentro dos princípios e objetivos do novo Programa de Formação de Professores da USP (CPL, 2004), pretende formar profissionais educadores que possam contribuir ativamente para a plena formação dos cidadãos e para o efetivo alcance dos objetivos dos Parâmetros Curriculares Nacionais, complementando o ensino de Ciências Naturais com conteúdos geológicos, somados a conteúdos de Biociências e a conteúdos de Geografia.

A Licenciatura em Geociências e Educação Ambiental tem como objetivo formar professores/educadores que atuem amplamente na educação formal e informal. Na educação formal estão contemplados o ensino fundamental e médio, o ensino técnico e também o ensino superior, em disciplinas da área de Ciências da Terra e da Natureza e em Educação Ambiental, em estreita interação com as outras Ciências, nas quais busca suas ferramentas de observação e interpretação (Física, Química e Matemática) e também em estreita associação com os conteúdos em Biociências, além da necessária associação com a Geografia.

O licenciado em questão deve levar aos alunos, em todos os níveis de ensino em que atue, o conhecimento do funcionamento do meio físico, dentro de uma perspectiva de evolução dinâmica e histórica da natureza ao longo do tempo geológico, com abordagem multidisciplinar, despertando os estudantes para o significado das múltiplas atividades humanas de utilização racional dos materiais geológicos e de ocupação e interferência no meio físico. Este conjunto de conhecimentos e idéias é essencial para promover uma nova relação do ser humano com a natureza, contribuindo para a formação de cidadãos críticos e responsáveis com relação à ocupação do planeta e utilização de seus diversos recursos, criando meios para diminuir o impacto ambiental das atividades econômicas, e também buscando soluções para os problemas já existentes de degradação do meio ambiente.

O projeto do curso foi estruturado visando ao preparo do educador para compreender a realidade social na qual se insere a escola em que atua, e para adaptar a sua atuação diante das rápidas transformações na sociedade, como agente principal na formação dos alunos de várias faixas etárias, tanto na escola básica (ensino fundamental e médio) como na de nível universitário e na de ensino técnico. Além disso, o licenciado neste curso deve estimular os alunos em sua curiosidade científica, incentivando-os à pesquisa e à reflexão ética perante a sociedade e o ambiente, dentro da perspectiva de aproveitamento das potencialidades locais para exemplificar os fenômenos naturais e as relações entre as atividades sócio-econômicas e a natureza, e ainda na perspectiva da sustentabilidade.

Em síntese, o licenciado em Geociências e Educação Ambiental levará à escola, por meio de atividades teóricas e práticas, o componente físico interdisciplinar ainda ausente para a compreensão geral do ambiente heterogêneo e dinâmico, atuando tanto em disciplinas em cujo conteúdo as Geociências estão fortemente presentes (Ciências da Natureza e também Geografia) como na própria Educação Ambiental e, ainda, em programas interdisciplinares de integração das várias disciplinas, previstos pelos PCN (Brasil, 1999).

Com relação às relações entre os conteúdos cursados no curso de Bacharelado em Geologia, já tradicional na Universidade de São Paulo, e este novo curso de Licenciatura, cumpre esclarecer as diferenças. No curso de Licenciatura, o graduando terá, em suas disciplinas obrigatórias, os conteúdos básicos sobre a dinâmica e a história terrestre, sem, no entanto, entrar nos conteúdos profissionalizantes da formação do geólogo; além disto, terá a formação pedagógica necessária à formação de um educador, além de disciplinas e atividades práticas específicas ao desenvolvimento de experiências no desenvolvimento e aplicação de recursos didáticos em Geociências e sua aplicação na educação ampla e na educação ambiental.

\section{Competências e habilidades}

O projeto do curso foi montado para dar ao licenciado a capacitação, em atendimento aos objetivos dos PCN na área de Ciências da Natureza, Matemática e suas Tecnologias, para levar os alunos a compreenderem e a 
utilizarem a ciência como elemento de interpretação e intervenção e a tecnologia como conhecimento sistemático de sentido prático. O licenciado deve estar habilitado a:

a. utilizar elementos e conhecimentos científicos e tecnológicos para diagnosticar e equacionar questões sociais e ambientais;

b. associar conhecimentos e métodos científicos com a tecnologia do sistema produtivo e de serviços;

c. reconhecer o sentido histórico da Ciência e da tecnologia, percebendo seu papel na vida humana em diferentes épocas e na capacidade humana de transformar o meio;

d. compreender as Ciências como construções humanas, entendendo seus modos de desenvolvimento por acumulação, continuidade ou ruptura de paradigmas;

e. relacionar o desenvolvimento científico com a transformação da sociedade;

f. entender a relação entre o desenvolvimento de Ciências Naturais e o desenvolvimento tecnológico;

g. associar as diferentes tecnologias disponíveis aos problemas aos quais se propõe solucionar e, ainda;

h. entender o impacto das tecnologias associadas às Ciências Naturais na sua vida pessoal, nos processos de produção, no desenvolvimento do conhecimento e na vida social.

O licenciado em Geociências e Educação Ambiental poderá tratar dos conteúdos geológicos que estão presentes nos PCN, de forma inédita no Brasil, de maneira atualizada e conectada às questões maiores do desenvolvimento da sociedade (ligadas ao esgotamento dos recursos e à degradação ambiental). O licenciado deverá estar apto a tratar esses temas sob as perspectivas:

a. da origem natural de todos os recursos materiais e energéticos utilizados;

b. da aquisição de uma idéia mais clara da real dimensão do tempo e das condições envolvidas na sua gênese, o que ampliará a compreensão do significado da sua utilização inconseqüente.

Sendo formado numa instituição de ensino fortemente ligada à pesquisa, o licenciado em questão terá noção do processo de construção do conhecimento geocientífico, ponto importante em sua formação. O licenciado terá, ainda, as habilidades necessárias para organizar programas interdisciplinares de estudo do meio, podendo aplicar trabalhos de campo, e considerando sempre que possível os parâmetros regionais e locais para dar um sentido prático e próximo aos conteúdos ministrados.

\section{Mercado de trabalho}

O mercado de trabalho para atuação do egresso do curso de Licenciatura em Geociências e Educação Ambiental configura-se no âmbito escolar e não-escolar. Destacam-se aqui algumas possibilidades concretas de atuação do futuro licenciado.

No caso da educação escolar, o licenciado pode atuar nas escolas de nível fundamental e médio em disciplinas nas quais são tratados, de forma contextualizada, temas específicos de Geociências e ainda temas e programas interdisciplinares envolvendo as Ciências da Natureza e a Educação Ambiental. Os Parâmetros Curriculares Nacionais, ao apresentarem os temas em Geociências dentro de diversas disciplinas das Ciências da Natureza, e mesmo nas Ciências Humanas, evidenciam e reconhecem a necessidade de um profissional educador com o perfil apresentado nesta proposta.

Ainda no ensino formal, deve-se mencionar as escolas técnicas estaduais e federais, que ministram diversas disciplinas de cunho geocientífico, inseridas na formação de profissionais de diversas áreas como Mineração, Edificações, Ambiente, Agricultura, Agrimensura, Topografia e Meio-Ambiente, mencionadas nas seguintes carreiras:

1. Técnico de Mineração (disciplinas: Desenho Técnico, Desenho Topográfico, Geologia, Topografia, Tecnologia e Meio Ambiente);

2. Técnico em Meio Ambiente (disciplinas: Química do Meio Ambiente, Elementos de Geologia, Geociências, Tecnologia de Controle da Poluição, Desenho Técnico);

3. Técnico em Agricultura (disciplinas: Desenho Técnico, Topografia, Tecnologia e Meio Ambiente);

4. Técnico em Edificações (disciplinas: Desenho Técnico, Topografia, Tecnologia e Meio Ambiente);

5. Técnico em Agrimensura (disciplinas: Desenho Técnico, Hidrologia, Solos, Topografia, Tecnologia e Meio Ambiente, Desenho Topográfico).

A grade curricular do novo curso propiciará, também, a formação de um profissional inédito e qualificado para atuar na formulação de Programas de Educação Ambiental. Em junho de 2002 foi assinado o Decreto Federal $n^{\circ} 4.281$, que regulamenta a Lei Federal $n^{\circ}$ 9.795, de 27.04.1999, que instituiu a Política Nacional de Educação Ambiental. Esta inclui a Educação Ambiental 
em todos os níveis e modalidades de ensino, a ser integrada às demais disciplinas e aos programas já vigentes de formação continuada de educadores. Nesta regulamentação, é também incentivada a implantação da Educação Ambiental em empresas, entidades de classe e instituições públicas e privadas, ampliando ainda mais a área de atuação do futuro educador em Geociências e Educação Ambiental.

Além disso, escolas privadas, em especial aquelas associadas à UNESCO no âmbito do Programa de Escolas Associadas - PEA, têm estabelecido disciplinas optativas na área de estudo do meio para as quais inexistem ainda educadores em número suficiente e com capacitação adequada havendo, portanto, um amplo espaço a ser ocupado pelo licenciado em Geociências e Educação Ambiental.

No tocante às atividades extra-curriculares da educação escolar, em especial do ensino fundamental e médio, o perfil do novo profissional é estratégico no sentido de complementar a formação dos estudantes em temas ligados aos processos geológicos em geral e, particularmente, ao ambiente da superfície terrestre.

Adicionalmente, deve ser considerado o mercado quantitativamente significativo e em franca expansão no país, representado por universidades e faculdades privadas de Engenharia, Geografia, Química e Biologia, que ministram disciplinas obrigatórias tais como Geologia Geral, Geologia Física, Mineralogia, Paleontologia, entre outras mais específicas (Cunha, 1995). Pesquisas da Unicamp na área de Educação aplicada às Geociências (Cunha, 1995), mostram a existência de disciplinas deste conjunto ministradas por profissionais não licenciados e formados fora da visão abrangente em Ciências da Natureza pretendida pela nova Licenciatura em Geociências e Educação Ambiental do IGc/USP.

Com relação à educação não-escolar, o licenciado em Geociências e Educação Ambiental encontrará campo de trabalho nas organizações que privilegiem a divulgação científica como museus, centros de Ciência, bibliotecas, parques, associações civis, organizações não-governamentais, empresas e ainda outras. Incluemse aqui aquelas ligadas ao planejamento de atividades de turismo com preocupações ecológicas, ou de programas de educação ambiental em empresas, seja para seus funcionários ou em atividades promovidas para a comunidade, nas quais poderá suprir uma lacuna deixada pela falta de conhecimento sobre a Terra, materiais e processos geológicos e riscos urbanos, entre outros temas, por parte das equipes participantes desta atividade. Tal lacuna decorre do fato de que poucos profissionais possuem formação específica em
Geociências. Além disso, o licenciado em Geociências e Educação Ambiental poderá participar de programas de formação em serviço dos professores do ensino fundamental que ainda não possuem nível universitário, programas estes em implantação em várias instituições de ensino superior.

Em síntese, a variedade de âmbitos de atuação indica que o Licenciado em Geociências e Educação Ambiental insere-se em importante demanda da sociedade e poderá suprir a lacuna atual na difusão do conhecimento do funcionamento do Sistema Terra, contribuindo assim para a formação de indivíduos responsáveis e críticos nas questões de uso e ocupação do solo e dos recursos naturais.

O curso tem também caráter prospectivo no mercado de trabalho, à semelhança das ações da USP que, ao criarem, em 1957, o curso de Geologia, vislumbraram uma profissão que se tornou estratégica para o desenvolvimento do país. No presente momento, a USP vivencia algo semelhante com a criação de cursos com formatos e temáticas inovadores nas mais diferentes áreas do conhecimento, sendo que a eventual regulamentação das profissões deverá ocorrer paulatinamente, como ocorreu com as consideradas mais tradicionais.

\section{Desenvolvimento dos conteúdos}

Para atingir os objetivos, dentro dos princípios expostos, foi composto um conjunto de disciplinas e atividades que, desde o início do curso, colocam o licenciando em contato com questões pedagógicas e aquelas inerentes à realidade da instituição escolar, além dos conteúdos específicos da área de conhecimento. $\mathrm{O}$ curso se desenvolve com a participação de outras unidades dedicadas ao estudo da natureza em seus diversos aspectos. São elas o Instituto Astronômico, Geofísico e de Ciências Atmosféricas, o Instituto Oceanográfico, o Instituto de Biociências e a Faculdade de Filosofia, Letras e Ciências Humanas, por meio de seus departamentos de Geografia e de Letras Modernas, e ainda, naturalmente, da Faculdade de Educação, cuja participação é a base do desenvolvimento dos aspectos pedagógicos do curso, em integração com o Instituto de Geociências em parte delas.

Assim, além da integração com conteúdos e profissionais de várias áreas, o licenciando terá contato com uma diversidade de temas das Ciências da Natureza e das Humanidades, de forma a embasar sua formação de caráter interdisciplinar e a possibilitar escolhas para aprofundamentos segundo seus interesses e vocações.

O conjunto de atividades didáticas, teóricas e 
práticas, definido no currículo do curso deve permitir a percepção, por parte do licenciando, da complexidade do contexto social e tecnológico moderno, proporcionando a reflexão sobre o papel do educador na construção contínua da sociedade, em geral, e do educador em Ciências Naturais e Ambientais, em particular, na formação dos alunos da escola básica, técnica e superior.

Sendo uma unidade da USP com forte vocação investigativa, com um complexo de laboratórios e centros de pesquisa, o IGc oferece aos licenciandos também a ocasião de vivenciar experiências na pesquisa científica, que constrói o conhecimento específico, contribuindo para a associação entre ensino e pesquisa; o licenciado, assim, saberá garantir, posteriormente ao curso, sua formação continuada, entendendo os caminhos da construção do conhecimento na área que escolheu. Ademais, com a demanda crescente por divulgação das Geociências, o IGc também oferece aos licenciandos a oportunidade de participação em atividades de extensão, seja no Museu de Geociências, seja nas atividades expositivas, palestras ou aulas práticas solicitadas por escolas, seja nas solicitações de apoio ao uso de materiais didáticos naturais ou modelos e materiais informatizados para ilustrar processos e materiais geológicos, ou, ainda, em cursos de atualização e reciclagem de professores da rede pública ou privada, em consonância com os princípios gerais da formação de professores por esta Universidade.

As atividades em instituições escolares, incluindo observação, planejamento, aplicação e avaliação, que ocorrem ao longo de boa parte do curso, no âmbito de várias disciplinas, inclusive nas disciplinas Metodologia do Ensino em Geociências e Educação Ambiental 1 e 2, representam etapas práticas que possibilitarão ao licenciando um contato com a realidade da Educação e das escolas; este contato será aproveitado para a preparação do futuro professor em sua missão de transformar a realidade por meio do ensino de sua disciplina específica, contribuindo para a formação mais completa dos estudantes, que se tornarão cidadãos mais responsáveis em seu cotidiano, que é impregnado da interação com o meio físico.

\section{Procedimentos didáticos}

As atividades didáticas devem ser desenvolvidas em salas de aula (aulas expositivas e práticas), no campo (aulas práticas de campo), em laboratórios diversos, bibliotecas e várias outras dependências como museus, centros de ensino ou divulgação de Ciências, e ainda nas escolas-campo de estágio.

\section{Atividades didáticas em sala-de-aula}

1. Aulas expositivas: são essencialmente expositivas e apoiadas por material ilustrativo de várias origens, principalmente das experiências investigativas dos docentes do IGc e das unidades que participam do curso. Têm como objetivo, basicamente, a apresentação de aspectos teóricos (ilustrados) dos ambientes geológicos diversos, dos processos geológicos e seus materiais, temas estes organizados na sua compartimentação disciplinar consagrada.

2. Aulas práticas: são atividades supervisionadas ou com acompanhamento muito próximo de professores, sendo desenvolvidas em salas de aula, em laboratórios ou no campo. Têm como objetivo proporcionar aos estudantes a oportunidade de manipularem materiais geológicos (incluindo os paleontológicos) diversos, possibilitando a aquisição de uma prática na identificação das espécies minerais e petrográficas, além do reconhecimento das características estruturais e morfológicas que permitem interpretação dos fenômenos geológicos e seus ambientes característicos, registrados em cada material.

\section{Atividades didáticas em laboratório}

Em laboratório, serão utilizados equipamentos que permitem a obtenção de informações detalhadas para a identificação de materiais geológicos em seus constituintes minerais e químicos, além de recursos de informática para o tratamento de informações geológicas (geoprocessamento).

\section{Atividades didáticas de campo}

As atividades de campo, tão fundamentais como as do curso de bacharelado do IGc, mas distintas, ocorrem em finais de semana e em dois períodos determinados das férias escolares, nas disciplinas de Seminários de Campo.

Estas atividades incluem a observação e interpretação da evolução e significado de paisagens e de exposições diversas de materiais e situações geológicas, além da preparação de coleções didáticas e de material gráfico (desenhos, fotografias, mapas, perfis) que permitam a reconstituição dos aspectos estudados no campo. Envolvem ainda o aprendizado de técnicas de campo, como descrição, coleta de dados e amostragem (solo, rocha, água), cartografia geológica de 
terrenos sedimentares, ígneos e metamórficos, incluindo confecção e interpretação de mapas e perfis geológicos. Neste particular, são aproveitadas ao máximo as exposições de rochas ou situações geológicas de interesse (parques, minerações, registros de desequilíbrios do meio como escorregamentos e outros, construções civis associadas ao uso e ocupação dos materiais naturais, como barragens etc.), particularmente as situadas no entorno de São Paulo, complementadas por outras áreas, de modo a contemplar toda a diversidade geológica necessária à formação do licenciando. Assim, ao final do curso, os licenciados estarão aptos a organizar atividades de campo para seus futuros alunos, de todos os níveis, como também a preparar coleções científicas com finalidades didáticas e ainda reconhecer e mostrar, na prática, as intervenções humanas na dinâmica natural que trazem impactos indesejáveis em diferentes níveis, além de discutir possíveis ações no sentido da remediação dos problemas.

\section{Organização do curso}

Em conformidade ao PFPUSP, o curso de Licenciatura em Geociências e Educação Ambiental está organizado em quatro blocos desenvolvidos de forma entrelaçada ao longo do curso; três deles referem-se à formação pedagógica geral e específica em Geociências e Educação Ambiental, e o quarto refere-se aos conhecimentos específicos em Geociências e Ambiente, em adição aos conhecimentos necessários de outras Ciências.

O entrelaçamento mencionado permite que as disciplinas pedagógicas permeiem o curso de Graduação desde o seu início, fazendo com que o licenciando possa refletir constantemente sobre a questão da educação durante todo o curso, evitando assim o apêndice das disciplinas pedagógicas isoladas de um curso em Geologia ou Ciências da Terra. Além disso, permite que o aluno exerça atividades pedagógicas específicas de forma progressiva, à medida que vai aumentando seu conhecimento nos conteúdos específicos.

\section{Formação pedagógica (Blocos I, II e III)}

\section{Bloco I}

\section{Iniciação à Licenciatura}

O primeiro bloco inicia-se com a disciplina Introdução aos Estudos da Educação, logo no primeiro semestre. Em atendimento ao novo Programa de Formação de Professores na USP, serão introduzidas neste bloco, quando da implementação do Projeto, as disciplinas por ele criadas, que pretendem sensibilizar e introduzir os alunos nas questões educacionais presentes na sociedade, sob os aspectos tanto da formação cultural ampla como da área específica de conhecimento, as Geociências. A primeira será escolhida entre os programas em Introdução aos Estudos de Educação credenciados no IGc por ocasião da implementação da nova Licenciatura da USP, visando à discussão de questões centrais da educação e da escolaridade básica em suas vinculações com o exercício da cidadania, e a segunda subsidiará a formação docente para educação básica ou profissional técnica, contemplando as perspectivas com que a área específica pode contribuir à formação ampla do cidadão.

Ainda no primeiro bloco, existem atividades acadêmico-científico-culturais que colocam os licenciandos em contato com os recursos culturais e naturais oferecidos na região geográfica (cidade e arredores), na perspectiva crítica de sua eventual contribuição para a sua formação profissional de educador na área específica. Assim, é aproveitada a infra-estrutura de museus, centros de ciência, bibliotecas, parques, associações civis, organizações não-governamentais e diversos outros ambientes propícios à realização de visitas e estudos. Estas atividades estão organizadas em quatro disciplinas obrigatórias (Atividades científicas e culturais 1, 2, 3 e 4), desenvolvidas preferencialmente ao longo dos quatro últimos semestres, num total de 7 créditos-trabalho (210 h).

Devem compor, ainda, o conteúdo deste bloco, disciplinas optativas dentro de um conjunto suficientemente flexível para permitir o enriquecimento cultural dos alunos, conforme suas vocações, expressas na escolha livre dessas disciplinas. À medida que o projeto for implantado, ao longo dos quatro primeiros anos de funcionamento do curso, o IGc deverá criar algumas disciplinas optativas para este conjunto.

\section{Bloco II \\ Fundamentos teóricos e práticos da educação}

O segundo bloco envolve, além das atividades teóricas, estágios em escolas, conforme estabelecido no novo Projeto de Formação de Professores da USP, com participação do IGc. Os licenciandos cursam programas em Políticas Públicas da Educação, em Didática e em Psicologia da Educação. Os programas, dentro de cada uma dessas três grandes áreas do saber 
educacional, inserem-se em projetos temáticos a serem propostos pelos docentes, abordando as questões sob variadas perspectivas. As atividades práticas fundamentais ligadas a este bloco dão aos alunos a oportunidade de vivências já com intervenção escolar, segundo sua escolha e dentro de seus interesses específicos. Os estágios das disciplinas obrigatórias ligadas aos conteúdos pedagógicos deste segundo bloco perfazem um total de $60 \mathrm{~h}$ (20 h para cada uma das três disciplinas).

\section{Bloco III}

\section{Fundamentos metodológicos do ensino}

O terceiro bloco inclui disciplinas e atividades que se referem diretamente à interface entre o saber pedagógico e o saber específico em Geociências, e finaliza a preparação do licenciando, que tem, nesta etapa, a ocasião de preparar, aplicar e avaliar suas intervenções supervisionadas nas escolas-campo de estágio, podendo incluir outras instituições de ensino ou divulgação cultural, em consonância com as diretrizes do novo Projeto de Formação de Professores da USP.

Nas disciplinas Metodologia de Ensino em Geociências e Educação Ambiental 1 e 2, será desenvolvido um projeto de ensino em Geociências para aplicação nas escolas-campo de estágio. O projeto deve ser fundamentado em termos de objetivo, justificativa e relevância, além de conter a especificação de conteúdos e estratégias pedagógicas que levem em conta a realidade geográfica/geológica/econômica/ social do alvo regional de sua aplicação, antes de sua aplicação no contexto das atividades práticas necessárias à formação do licenciado. Assim, este trabalho sintetizará as atividades práticas, representando o fechamento de seu aprendizado e reflexão pedagógica aplicada ao desenvolvimento dos alunos sob o ponto de vista da relação Geociências, educação e sociedade.

Os estágios mais densos dentro deste curso de Licenciatura estão nas disciplinas de Metodologia de Ensino em Geociências 1 e 2, cada uma com 120 h de práticas, como já ocorre tradicionalmente nas disciplinas de Metodologia de Ensino para várias áreas do conhecimento. Além disso, a disciplina Recursos Didáticos em Geociências e a disciplina de Educação Ambiental do último ano terão mais 80 h de estágios cada uma, somando, portanto, 400 h de práticas neste bloco, na forma de estágios pedagógicos supervisionados ligados aos conteúdos específicos.

\section{Conhecimentos específicos (Bloco IV)}

\section{Bloco IV \\ Formação específica}

Considerando o caráter multidisciplinar envolvido na compreensão da história, organização e funcionamento do planeta, o curso inicia-se com uma disciplina que apresenta o sistema geológico global. Por meio dela, o aluno tem uma visão ampla da complexidade da dinâmica da Terra, da seqüência dos fenômenos que a formaram como a vemos hoje, além das possibilidades de ocupação e utilização dos ambientes e dos materiais. Paralelamente, são desenvolvidas disciplinas básicas das Ciências necessárias ao entendimento dos processos geológicos e dos problemas ambientais e das relações da vida com o ambiente físico, que se desenvolvem, principalmente, no início do curso (Física, Química, Matemática e Biologia).

Neste bloco, serão cursadas, ainda, as disciplinas necessárias à compreensão detalhada da visão global da Terra oferecida na primeira disciplina do curso, e que tratam dos materiais naturais, sua distribuição nos diversos ambientes terrestres e sua evolução no Tempo Geológico, sua vinculação com os processos da Biosfera, bem como suas possíveis aplicações no desenvolvimento sócio-econômico da sociedade, culminando com os aspectos ambientais da ocupação do ambiente natural e do uso dos recursos naturais com vistas à sustentabilidade.

A definição dos conteúdos das diversas disciplinas busca evidenciar a conexão das disciplinas básicas, como Física e Química, com as Ciências da Terra, e, também, a conexão da evolução da vida com a dinâmica e evolução terrestre, formando a base geocientífica necessária para atuação na Educação Ambiental. Além disso, a formação levada a cabo por este curso terá interação com a Geografia, na medida em que poderá ser utilizada na preparação do estudo das relações da humanidade com a natureza, que atinge parcela recente do tempo geológico (Carneiro et al., 2001).

Nesta parte do curso, também há atividades práticas com supervisão docente, referentes aos Seminários de Campo 1 e 2, que constituem disciplinas fundamentais à reflexão, discussão e assimilação dos conteúdos específicos das várias disciplinas teóricas de Geociências já cursadas. Nestas duas disciplinas obrigatórias, há uma carga horária prática de 75 h cada uma, incluindo, além das 
atividades em campo, o tempo de preparo de atividades simuladas de campo como exercício geológicopedagógico e ambiental-pedagógico.

Nas disciplinas obrigatórias de conhecimentos específicos são previstas atividades práticas de campo supervisionadas, num total de 60 h. Como atividade obrigatória, os alunos do curso de Licenciatura em Geociências e Educação Ambiental cumprirão, ainda, uma carga horária de 340 h de práticas supervisionadas ao longo do curso, no atendimento a estudantes e professores da educação básica no âmbito das atividades de extensão realizadas pelo Museu de Geociências, pela Biblioteca, pelo Laboratório de Apoio Didático, pela Oficina de Réplicas de Fósseis e dos grupos de divulgação das Geociências, além de atividades de monitoria nos cursos de férias oferecidos pelo IGc a professores da rede pública e privada.

Principalmente a partir do segundo ano, os alunos deverão escolher disciplinas optativas, de modo a cumprir um total de 16 créditos, dentre disciplinas internas e externas ao IGc, com conteúdos em Educação e Formação científico-cultural, bem como em áreas específicas das Ciências da Natureza e, também, de outras áreas.

\section{Grade curricular e carga horária}

A grade curricular do curso (Quadro 1) sofrerá algumas modificações no final do ano de 2005, devido à adaptação necessária ao Programa de Formação de Professores da USP (CPL, 2004). A grade modificada será disponibilizada na rede, após sua oficialização pelos órgãos competentes da Pró-Reitoria de Graduação da USP.

A carga horária atual do curso totaliza 3.055 h e atende as exigências legais (LDBEN e resolução CNE/CP 2/2002), que estabelecem que os cursos de licenciatura, de graduação plena, devem garantir em seus projetos pedagógicos, quatro componentes comuns (listados a seguir), totalizando pelo menos $2.800 \mathrm{~h}$, ao longo de, no mínimo, três anos:

a. prática como componente curricular (duração mínima de 400 h);

b. estágio curricular supervisionado (duração mínima de $400 \mathrm{~h}$ );

c. conteúdos curriculares de natureza científicocultural (1.800 h);

d. atividades acadêmico-científico-culturais (duração mínima de 200 h).

\section{CONCLUSÃO}

A criação do curso de Licenciatura em Geociências e Educação Ambiental no Instituto de Geociências da Universidade de São Paulo insere-se num conjunto de iniciativas que esta Unidade da USP vem tomando há vários anos, no sentido de divulgar, de várias formas, o conhecimento sobre a dinâmica natural com a qual a origem e a evolução da Vida mantêm relações de total interdependência. Este conteúdo complementa o estudo das Ciências da Natureza normalmente efetuado na educação escolar.

Nesta fase histórica de reconhecimento por parte da sociedade sobre a necessidade de uma nova postura do cidadão com relação ao uso e ocupação do planeta, os produtos acadêmicos gerados nas diversas atividades do curso de Licenciatura em Geociências e Educação Ambiental, como relatórios, modelos etc., podem representar contribuições significativas ao acervo pedagógico da Universidade e das escolas ou outras instituições em que se tenham desenvolvido as atividades de aplicação de projetos de ensino e dos estágios supervisionados.

A criação da Licenciatura em Geociências e Educação Ambiental preencherá uma lacuna deixada na atividade dos profissionais em Geociências. As descobertas e avanços nas Geociências têm ficado restritos aos círculos especializados, privando os ambientes educacionais, escolares e não-escolares, de informações geocientíficas precisas, atualizadas e integradas, prejudicando a conscientização sobre a complexa dinâmica do planeta. Justamente esta conscientização é que contribuirá para a formação de cidadãos capazes de opinar de forma consciente sobre as questões de ocupação e uso do ambiente pela sociedade, formação esta essencial para o alcance do desenvolvimento sustentável e dos objetivos das diretrizes curriculares traçadas para a educação básica.

Espera-se que os futuros educadores formados neste curso atuem amplamente na educação formal e informal, contemplando o ensino fundamental, médio e o ensino técnico, em disciplinas da área de Ciências da Terra e da Natureza e em Educação Ambiental, em estreita interação com a Física, Química e Matemática, e também em estreita associação com os conteúdos em Biociências, além da necessária associação com a Geografia, entre as Ciências Humanas, e também atuando nas organizações que privilegiem a divulgação científica como museus, centros de Ciência, bibliotecas, parques, associações civis, Organizações não-Governamentais e empresas com programas de educação ambiental. 
Quadro 1. Grade curricular da Licenciatura em Geociências e Educação Ambiental, com as informações sobre carga horária, créditos e semestre ideal. (*) Disciplinas anuais. (ID) Disciplinas interdepartamentais.

\begin{tabular}{|c|c|c|c|c|c|c|c|c|}
\hline \multirow{2}{*}{\multicolumn{2}{|c|}{$\begin{array}{l}\text { Disciplinas obrigatórias } \\
\text { Seqüência aconselhada }\end{array}$}} & \multirow{2}{*}{$\begin{array}{l}\text { Disciplina } \\
\text { Requisito }\end{array}$} & \multicolumn{3}{|c|}{ Créditos } & \multicolumn{2}{|c|}{ Carga } & \multirow{2}{*}{$\begin{array}{l}\text { Sem. } \\
\text { Ideal }\end{array}$} \\
\hline & & & Aula & Trab. & Total & Sem. & Anual & \\
\hline 0440101 & Sistema Terra (ID) $\left(^{*}\right)$ & -- & 8 & 0 & 8 & & 120 & $1 \% 2^{\circ}$ \\
\hline 1400200 & Física da Terra e do Universo para Licenciatura em Geociências & -- & 4 & 0 & 4 & 60 & & $1^{\circ}$ \\
\hline FGE0160 & Ótica & -- & 2 & 0 & 2 & 30 & & $1^{\circ}$ \\
\hline MAT0140 & Matemática para Geociências & -- & 4 & 0 & 4 & 60 & & $1^{\circ}$ \\
\hline EDF0283 & Introdução aos Estudos da Educação & -- & 4 & 0 & 4 & 60 & & $1^{\circ}$ \\
\hline \multirow[t]{2}{*}{0440102} & Metodologia Científica em Geociências (ID) & -- & 2 & 0 & 2 & 30 & & $1^{\circ}$ \\
\hline & & Total & 24 & 0 & 24 & 240 & 120 & \\
\hline$\overline{\text { QFL0607 }}$ & Química Básica & -- & 4 & 0 & 4 & 60 & & $2^{\circ}$ \\
\hline FLC0287 & Língua Portuguesa & -- & 2 & 0 & 2 & 30 & & $2^{\circ}$ \\
\hline FAP0151 & Fundamentos da Mecânica & -- & 4 & 0 & 4 & 60 & & $2^{\circ}$ \\
\hline \multirow[t]{2}{*}{ EDF0288 } & Psicologia da Educação & -- & 4 & 0 & 4 & 60 & & $2^{\circ}$ \\
\hline & & Total $^{-}$ & 14 & 0 & 14 & 210 & & \\
\hline$\overline{G M G 0221}$ & Minerais e Rochas I & 0440101 & 3 & 1 & 4 & 75 & & $3^{\circ}$ \\
\hline 0440201 & Geoquímica para Licenciatura (ID) & 0440101/QFL0607 & 2 & 0 & 2 & 30 & & $3^{\circ}$ \\
\hline GSA0213 & Sedimentologia para Licenciatura & 0440101 & 2 & 0 & 2 & 30 & & $3^{\circ}$ \\
\hline GSA0215 & Computação & -- & 2 & 1 & 3 & 60 & & $3^{\circ}$ \\
\hline FGE0357 & Oscilações e Ondas & -- & 2 & 0 & 2 & 30 & & $3^{\circ}$ \\
\hline $\mathrm{BIO} 0103$ & Biologia & -- & 4 & 0 & 4 & 60 & & $3^{\circ}$ \\
\hline \multirow[t]{2}{*}{ EDM401 } & Didática & -- & 4 & 0 & 4 & 60 & & $3^{\circ}$ \\
\hline & & Total & 19 & 2 & 21 & 345 & & \\
\hline GMG0222 & Minerais e Rochas II & GMG0221 & 3 & 1 & 4 & 75 & & $4^{\circ}$ \\
\hline GSA0216 & Estratigrafia para Licenciatura & GSA0213 & 2 & 0 & 2 & 30 & & $4^{\circ}$ \\
\hline GSA0218 & Paleontologia para Licenciatura & 0440101/BIO0103 & 2 & 1 & 3 & 60 & & $4^{\circ}$ \\
\hline AGG0110 & Elementos de Geofísica & - & 4 & 0 & 4 & 60 & & $4^{\circ}$ \\
\hline AGA0104 & Astronomia para Licenciatura em Geociências & - & 2 & 0 & 2 & 30 & & $4^{\circ}$ \\
\hline FLC0288 & Técnicas de Redação & - & 2 & 0 & 2 & 30 & & $4^{\circ}$ \\
\hline \multirow[t]{2}{*}{2100106} & Sistema Oceano & - & 4 & 0 & 4 & 60 & & $4^{\circ}$ \\
\hline & & Total & 19 & 2 & 21 & 345 & & \\
\hline GMG0301 & Tectônica & GSA0216 & 3 & 1 & 4 & 75 & & $5^{\circ}$ \\
\hline \multirow[t]{3}{*}{0440041} & História da Terra e Evolução Biológica (IGc + IB) & - & 4 & 0 & 4 & 60 & & $5^{\circ}$ \\
\hline & Pedologia para Licenciatura & - & 2 & 0 & 2 & 30 & & $5^{\circ}$ \\
\hline & Geomorfologia para Licenciatura & - & 2 & 0 & 2 & 30 & & $5^{\circ}$ \\
\hline ACA0225 & Meteorologia para Licenciatura & - & 2 & 0 & 2 & 30 & & $5^{\circ}$ \\
\hline BIE0210 & Ecologia & - & 4 & 0 & 4 & 60 & & $5^{\circ}$ \\
\hline \multirow[t]{2}{*}{0440303} & Atividades Científicas e Culturais I & - & 0 & 1 & 1 & 30 & & $5^{\circ}$ \\
\hline & & Total & 17 & 2 & 19 & 315 & & \\
\hline 0440312 & Recursos Naturais I (ID) & GMG0222 & 2 & 0 & 2 & 30 & & $6^{\circ}$ \\
\hline 0440314 & Geologia do Brasil para Licenciatura (ID) & GMG0301 & 2 & 1 & 3 & 60 & & $6^{\circ}$ \\
\hline 0440316 & Geologia Ambiental I (ID) & 0440201 & 2 & 0 & 2 & 30 & & $6^{\circ}$ \\
\hline GSA0320 & Geotecnologia & - & 3 & 1 & 4 & 75 & & $6^{\circ}$ \\
\hline 0440318 & Recursos Didáticos em Geociências (ID) & 0440101/EDM0401 & 3 & 3 & 6 & 135 & & $6^{\circ}$ \\
\hline \multirow[t]{2}{*}{0440304} & Atividades Científicas e Culturais II & - & 0 & 1 & 1 & 30 & & $6^{\circ}$ \\
\hline & & Total & 12 & 6 & 18 & 360 & & \\
\hline 0440001 & Seminários de campo I (ID) - Intersemestral & GMG0222/GMG0301 & 3 & 1 & 4 & 75 & & \\
\hline 0440413 & Recursos Naturais II (ID) & 0440312 & 2 & 0 & 2 & 30 & & $7^{\circ}$ \\
\hline 0440417 & Geologia Ambiental II (ID) & 0440316 & 2 & 0 & 2 & 30 & & $7^{\circ}$ \\
\hline EDA0461 & Política e Organização da Educação Básica no Brasil & - & 4 & 0 & 4 & 60 & & $7^{\circ}$ \\
\hline EDM451 & Metodologia do Ensino em Geociências e Educação Ambiental I & 0440318 & 4 & 4 & 8 & 180 & & $7^{\circ}$ \\
\hline \multirow[t]{2}{*}{0440421} & Atividades Científicas e Culturais III & - & 0 & 2 & 2 & 60 & & $7^{\circ}$ \\
\hline & & Total & 12 & 6 & 18 & 360 & & \\
\hline 0440002 & Seminários de campo II (ID) - Intersemestral & 0440001 & 3 & 1 & 4 & 75 & & \\
\hline EDM452 & Metodologia do Ensino em Geociências e Educação Ambiental II & 0440405 & 4 & 4 & 8 & 180 & & $8^{\circ}$ \\
\hline 0440418 & Educação Ambiental para Licenciatura (ID) & $0440318 / 0440417$ & 2 & 3 & 5 & 120 & & $8^{\circ}$ \\
\hline CJE0499 & História da Ciência & - & 2 & 0 & 2 & 30 & & $8^{\circ}$ \\
\hline \multirow[t]{6}{*}{0440422} & Atividades Científicas e Culturais IV & - & 0 & 3 & 3 & 120 & & $8^{\circ}$ \\
\hline & & Total $^{-}$ & 8 & 10 & 18 & 450 & & \\
\hline & Créditos e Carga Horária necessários & ra conclusão do Curso & & & & & & \\
\hline & Obrigatórias: créd. aula $=131=1.965 \mathrm{r}$ & créd. trab. $=30=900 \mathrm{~h}$. & & & & & & \\
\hline & Optativas: créd. aula $=16=240 \mathrm{~h} /$ créc & $\mathrm{rab} .=0=0 \mathrm{~h}$ & & & & & & \\
\hline & Total $=177=3.105 \mathrm{~h}$ & & & & & & & \\
\hline
\end{tabular}

Nota importante: a estrutura curricular acima é a vigente em 2005, antes das modificações necessárias para adaptação ao Programa de Formação de Professores da USP (PFPUSP) (CPL, 2004). A nova estrutura curricular estará disponível na rede de endereço www.igc.usp.br/ensino/graduacao. 


\section{REFERÊNCIAS BIBLIOGRÁFICAS}

BRASIL. Ministério da Educação. Secretaria de Educação Média e Tecnológica. Parâmetros curriculares nacionais: ensino médio. Brasília: Ministério da Educação, 1999. 364 p.

CARNEIRO, C. D. R.; GONÇALVES, P. W.; NEGRÃO, O. B. M.; CUNHA, C. A. L. Ciência do Sistema Terra e o entendimento da "máquina” planetária em que vivemos. Geonomos, Belo Horizonte, v. 9, n. 1, p.1-8, 2001.

CPL - COMISSÃO PERMANENTE DE LICENCIATURAS. Programa de Formação de Professores. Pró-Reitoria de Graduação da Universidade de São Paulo. São Paulo, 2004. 37 p.

CUNHA, C. A. L. Geologia introdutória nas instituições de ensino superior no Brasil: análise dos cursos de ciências e geografia. 1995. 268 p. Tese (Doutorado) Faculdade de Educação, Universidade Estadual de Campinas, Campinas.

TEIXEIRA, W.; TOLEDO, M. C. M.; FAIRCHILD, T. R.; TAIOLI, F. Decifrando a Terra. São Paulo: Oficina de Textos, 2000.557p. 